\title{
O conceito de Estado \\ Desenvolvimentista e sua utilidade para os casos brasileiro e argentino
}

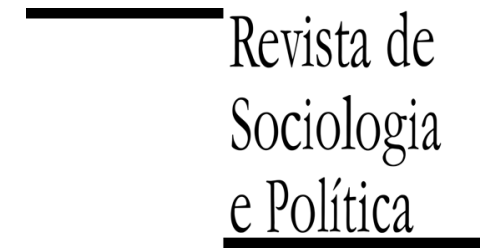

DOI 10.1590/1678-987314225205

\author{
Renato Perissinotto
}

\begin{abstract}
RESUMO
O texto analisa o conceito de Estado Desenvolvimentista e sua utilidade para pensar comparativamente os casos de Brasil e Argentina. O método da pesquisa é comparativo e o material utilizado é a extensa bibliografia sobre o conceito e sobre os dois países, além de algumas fontes empíricas, notadamente entrevistas com decisores da área econômica. A pesquisa indica até o presente momento a importância das elites políticas e burocráticas para explicar as diferenças de desempenho no processo de industrialização de Brasil e Argentina. O desenho comparativo da pesquisa, amparada num conceito que, ele próprio, nasceu de pesquisas comparativas, contribui para melhor delimitar as causas não econômicas do desenvolvimento.
\end{abstract}

PALAVRAS-CHAVE: Estado Desenvolvimentista; Brasil; Argentina; industrialização; 1930-1966.

Recebido em 9 de Janeiro de 2014. Aprovado em 14 de Julho de 2014.

\section{Introdução ${ }^{1}$}

\footnotetext{
${ }^{1} \mathrm{O}$ autor gostaria de agradecer aos pareceristas anônimos da Revista de Sociologia e Política pelos comentários ao texto.
}

$\mathrm{E}$ ste artigo resulta de uma pesquisa comparativa sobre o desenvolvimento industrial de Brasil e Argentina após 1930. A literatura econômica sobre os dois países (literatura, aliás, raramente comparativa) revela que, a despeito da flagrante superioridade econômica argentina nos começos do século XX, o Brasil, entre os anos 1930 e 1960, industrializa-se mais rápida e solidamente que aquele país (Ffrench-Davis, Muñoz \& Palma 1998, pp. 177178; Fajnzylber 1983, p. 151; Dorfmann 1983, pp. 216-221 e 580-581; Cortés Conde 2009, pp. 6-8). Para qualquer argentino ou brasileiro que vivesse durante os anos 1920 ou 1930 tais achados da historiografia econômica seriam vistos, naquele momento, como algo absolutamente surpreendente. Afinal, como poderia a Argentina, então situada entre as mais poderosas economias do mundo, ser superada pelo vizinho de território gigantesco, mas de economia acanhada?

Esse fato contraintuitivo nos levou a indagar acerca das razões que poderiam ajudar a entender a diferença de desempenho no processo de industrialização desses dois países nos anos posteriores a 1930. A nossa pesquisa tem mostrado que uma das razões fundamentais (mas certamente não a única) reside no processo de state-building que se deu diferentemente em ambos os países após aquele ano e, por conseguinte, na presença de uma burocracia econômica estável e orientada por uma ideologia de tipo desenvolvimentista apenas no caso brasileiro. O objetivo precípuo deste texto não é apresentar ao leitor dados sobre essa burocracia, mas antes discutir um conceito que nos parece particularmente útil para abordar o problema do desenvolvimento, a saber, o conceito de "Estado Desenvolvimentista" (doravante ED).

Para tanto, o artigo divide-se em três seções. Na primeira fazemos uma brevíssima recuperação da genealogia deste conceito; na segunda seção, descrevemos o seu conteúdo, dando especial atenção às três dimensões que, na nossa visão, caracterizam-no: a dimensão contextual, a dimensão institucional e a 
dimensão volitiva; em seguida, procuramos apresentar a utilidade desse conceito para pensar o caso brasileiro (tendo sempre implícita a comparação com o caso argentino). Por fim, à guisa de conclusão, enfatizamos aquelas que nos parecem ser as principais vantagens de se lançar mão desse conceito para o estudo comparado de processos de desenvolvimento econômico.

\section{Uma breve genealogia do conceito de Estado desenvolvimentista}

Num texto de 1963, intitulado "Concepts and Generalizations in Comparative Sociological Studies", Reinhard Bendix afirmava que "estudos comparativos iluminam o sentido de universais sociológicos exibindo o elenco de 'soluções' que os homens encontraram para um dado problema em diferentes sociedades" (Bendix 1963, p. 535; sem grifos no original).

Os universais sociológicos seriam, ainda segundo Bendix, aqueles grandes processos sociais com propensão a se alastrarem por várias regiões do globo ao longo da história, tais como a urbanização dos espaços, o assalariamento das relações de trabalho, a burocratização das grandes organizações estatais e privadas, a profissionalização política nas democracias representativas etc. No entanto, esses "universais sociológicos" não ocorreriam exatamente da mesma maneira em todos os lugares. Dependendo dos contextos históricos, de suas singularidades, da sequência e do timing dos acontecimentos, o "elenco de soluções" mobilizado pelos homens e mulheres de lugares diversos conduziria o processo de consolidação daqueles universais sociológicos por caminhos diferentes, produzindo resultados distintos. Para Bendix, muito mais interessante do que constatar o caráter "universal" desses fenômenos é captar o sentido particular que eles adquirem em função das soluções diferentes propostas por pessoas e grupos sociais distintos em contextos históricos diversos. Esse seria o objetivo fundamental da comparação: identificar as singularidades que explicitam o sentido local daqueles universais.

Segundo o mesmo Bendix, a industrialização se constitui num desses universais sociológicos e o seu processo de implementação, sobretudo em países que a ela chegaram tardiamente, depende muito da presença de grupos sociais dispostos a assumi-la como "projeto" e a sustentá-la politicamente contra forças dedicadas a defender o "antigo regime". Sendo assim, os atributos sociais, econômicos e ideológicos desses grupos são importantes na medida em que afetam o desenvolvimento econômico futuro de uma nação, sua direção, seu ritmo e sua intensidade.

Nesse sentido, acreditamos que podemos aplicar ao problema da industrialização a mesma questão que Max Weber (1981) formulou no seu clássico ensaio sobre a psicologia social das religiões mundiais. Neste texto, Weber afirma que o conteúdo assumido pela ética econômica das religiões depende não apenas das fontes propriamente religiosas (ainda que dependa principalmente delas), mas também dos atributos das camadas socialmente disponíveis para assumirem a tarefa de elaborar a teoria dessas crenças e conduzir a sua aplicação prática. As especificidades desses grupos, diz Weber, são sociologicamente significativas na medida em que suas características afetam o desenvolvimento futuro dessas religiões. Nesse sentido, perguntar-se "quais grupos" estão disponíveis num dado contexto para se transformarem em "portadores sociais" (träger) da nova crença é fundamental do ponto de vista da Sociologia.

O problema da industrialização em países de economia primário-exportadora, como o Brasil e a Argentina, pode ser colocado nos mesmos termos. Quando esses países se defrontam com a conjuntura crítica de 1929 e a eles se apresenta a possibilidade de trilhar o caminho da industrialização torna-se então pertinente perguntar quais deles contam com grupos sociais dispostos a serem 
os portadores políticos dessa tarefa e como seus atributos afetariam a natureza do desenvolvimento econômico posterior.

Esse modo de formular a questão sobre o processo de industrialização, que destaca os aspectos atitudinais como uma das suas causas, tem forte tradição entre os próprios economistas.

Salvo engano, essa proposição foi feita inicialmente no clássico trabalho de Alexander Gerschenkron (1976), Economic Backwardness in Historical Perspective. A Book of Essays, publicado originalmente em 1962. Neste livro seminal, o autor enfatiza a importância da dimensão política do processo de industrialização, especialmente em países que chegam a ela tardiamente e nos quais a intervenção estatal ocupa lugar central. Nesses casos, continua Gerschenckron, atitudes favoráveis ou contrárias à industrialização são tão mais importantes enquanto variáveis explicativas desse processo quanto mais se cristalizarem em ações governamentais. Por essa razão é que "uma abordagem principalmente política da história industrial” seria fundamental (idem, p. 52).

Albert O. Hirschman defende posição similar. Para este autor, o desenvolvimento econômico não depende tanto de se encontrar a combinação ótima de recursos e fatores (os pré-requisitos da industrialização), mas antes de uma atitude favorável a ele e da identificação de recursos e habilidades que estão escondidos e mal utilizados. Para essa tarefa é fundamental a existência de um "agente de ligação" (binding agent) que tome "decisões desenvolvimentistas", isto é, que promova as mudanças e reformas institucionais necessárias, assim como as decisões de investimento propriamente ditas. Nesse sentido, o desenvolvimento econômico certamente é condicionado por condições objetivas, mas, como toda ação humana, suas dificuldades iniciam-se "na mente" (Hirschman 1964, pp. 5, 11 e 26, nota 33).

Desde então, uma vasta bibliografia seguiu a orientação analítica geral inaugurada pelo livro fundamental de Gerschenkron ${ }^{2}$ e parte dela acabou desembocando na formulação do conceito de "Estado Desenvolvimentista".

\section{As três dimensões do conceito}

2 Ver, por exemplo, Hirschman (1964), Trimberger (1978), Johnson (1982), Evans e Stephens (1988), Evans (1995), Leftwich (1995; 2000; 2010), Evans e Wolfson (1996), Kiely (1998), Kohli
O conceito de "Estado Desenvolvimentista" foi empregado inicialmente para pensar o desempenho econômico dos países do leste e do sudeste asiáticos, em particular Japão, Coreia do Sul, Taiwan e Singapura. Foi elaborado primeiramente por Chalmers Johnson (1982) no seu já clássico livro sobre o papel do Ministério do Comércio Exterior e da Indústria do Japão na promoção do desenvolvimento econômico daquele país. Mais recentemente, um conjunto de outros autores, a partir das considerações iniciais de Johnson, dedicou-se à sistematização do conceito. Com base nessa literatura, acreditamos ser possível dizer que o conceito de ED comporta três dimensões interligadas: uma dimensão contextual, uma dimensão institucional e uma dimensão volitiva. Apresentamos a seguir o que entendemos por cada uma delas.

III.1. A dimensão contextual do ED

\footnotetext{
3 Fatores históricos extra-estatais, como o contexto internacional ou a natureza da relação com as classes sociais, são importantes na medida em que são determinantes da
}

Essa dimensão refere-se a certas condições exteriores ao Estado que facilitariam o surgimento de um ED. Segundo a literatura, há certos contextos nacionais e internacionais que favorecem o aparecimento das estruturas institucionais características deste tipo de Estado $^{3}$.

Quanto ao contexto nacional, Peter Evans (1995), a partir da formulação do seu conceito de "autonomia inserida", observa que um ED é aquele que, entre outras coisas, consegue desenvolver mecanismos institucionais que permitem à sua burocracia manter contato permanente com grupos e classes sociais estra- 
configuração institucional do Estado. Nesse sentido, discordamos da crítica de Schneider (1999, p. 279) a Chalmers Johnson, segundo a qual a definição de um tipo de Estado não deveria contemplar dimensões exteriores ao mesmo.

${ }^{4}$ Em casos extremos, o Estado cria os seus interlocutores antes de eles existirem de maneira autônoma na sociedade civil. Esse é o caso da Coreia do Sul, em que "o recurso ao Estado vem primeiro, seguido pela tentativa consciente ou inconsciente de criar a indústria, o "big business' [...] e depois, e apenas depois, a "sociedade"" (Cumings 1999, p. 89). tégicos, de modo a coletar informações necessárias para o processo decisório e a legitimá-lo por meio de uma participação ativa desses setores na tomada de decisão, sem, no entanto, deixar que o Estado se torne presa dos interesses imediatos e privatizantes desses grupos.

No entanto, para que o Estado consiga estabelecer esse diálogo e institucionalizar a autonomia inserida que o caracteriza, é preciso que o contexto social em que ele atua não seja muito fragmentado. Seria pouco provável que um Estado com estrutura interna coerente fosse capaz de estabelecer conexões com uma estrutura social excessivamente fraccionada, sem interlocutores claros e organizados. Nessas condições, seria difícil criar laços com a sociedade e construir a autonomia inserida (idem, p. 557). Dito de outro modo, uma estrutura social com grupos e classes razoavelmente estruturados e organizados como atores coletivos é uma condição muito importante para a ascensão de um $\mathrm{ED}^{4}$.

Do ponto de vista do contexto internacional, a literatura aponta a situação de guerra efetiva ou de ameaça externa como fundamental para dar origem a algo que poderíamos chamar de "nacionalismo prático", isto é, um nacionalismo que se traduz efetivamente e eficazmente em state-building e políticas econômicas cujo resultado é o desenvolvimento e a industrialização com vistas a se equiparar às potências que representam ameaça à soberania nacional. Portanto, a forte e explosiva conjugação entre uma tradição nacionalista e ameaças concretas à integridade nacional são elementos muito importantes para a produção de EDs, como evidenciam os casos do Japão e da Coreia do $\mathrm{Sul}^{5}$.

III.2. A dimensão institucional do ED

${ }^{5}$ Em geral, segundo Johnson, essa inclinação modernizante tem claras pretensões nacionalistas, que, por sua vez, crescem num ambiente de intensa hostilidade externa. Nesse sentido, a política industrial é vista como servindo ao propósito de se equiparar ou superar a economia de outras nações concorrentes Johnson (1982, pp. 19-22, 24). Ver também Leftwich (1995, p. 401).

${ }^{6}$ Não se trata, na verdade, de pensar apenas em termos de "presença" ou "ausência", mas também em termos de intensidade. Por essa razão, não achamos útil a distinção de Schneider (1999, pp. 278 e 293) entre "Desarrollista State" e "Developmental State" como se fossem dois tipos qualitativamente distintos. Antes, preferimos pensar a institucionalização como um continuun, como faz, aliás, esse mesmo autor em outro texto (Schneider 1991, p. 32).

${ }^{7}$ Uma questão central quanto a este ponto, impossível de ser desenvolvida aqui, refere-se à relação entre ED e autoritarismo. Sobre esse
No que se refere à dimensão institucional, dois aspectos são importantes.

Primeiramente, um ED deve contar com a presença ${ }^{6}$ de uma burocracia bem ordenada, tecnicamente competente, recrutada por procedimentos específicos, portadora de um ethos burocrático e de um acentuado esprit de corps e protegida de pressões clientelistas. Sendo pouco provável que todo o aparelho estatal se organize de acordo com os princípios típicos que definem a burocracia moderna, é fundamental, entretanto, que as agências responsáveis pelas decisões desenvolvimentistas sejam estruturadas de acordo com eles (Johnson 1982; Evans 1995; Leftwich 1995; 2000; Evans \& Wolfson 1996; WooCumings 1999).

Segundo Johnson (1982, pp. 20-21), uma característica central do ED é um processo decisório sobre a política econômica amplamente dominado por burocratas econômicos razoavelmente autônomos, em vez de controlado por políticos eleitos ${ }^{7}$. No caso japonês, descrito exaustivamente pelo autor, o processo decisório do ED é controlado por funcionários dos ministérios das Finanças, da Indústria, da Construção, dos Transportes e de outras agências de planejamento econômico. Essas agências atraem os indivíduos mais talentosos e competentes, graduados nas melhores universidades do país. Ainda que haja influência de grupos de pressão e de políticos, a elite burocrática toma a maioria das decisões mais importantes, esboça virtualmente quase toda legislação, controla o orçamento nacional e é a fonte da maior parte de inovações em políticas públicas. Em todos os EDs analisados pela literatura identifica-se a existência de uma "agência piloto" profundamente marcada por essas características (Woo-Cumings 1999, p. 13) ${ }^{8}$. Portanto, não basta que exista uma burocracia, mas é necessário que ela concentre em suas mãos os instrumentos de formulação e implementação de decisões cujo objetivo seja produzir o desenvolvimento econômico e a industrialização. 
tema, ver Cumings (1999, p. 70), Leftwich (2000, pp. 182-187; 1995); Loriaux (1999, pp. 236 e 260-266) e Schneider (1999, pp. 278, 298 e 303).

${ }^{8}$ Por exemplo, o Ministério da Indústria e do Comércio Exterior, no Japão; o Conselho para o Planejamento Econômico e o Desenvolvimento, de Taiwan; o Conselho de Planejamento Econômico, da Coreia do Sul; o Conselho de Desenvolvimento Econômico, de Singapura (Leftwich 1995, pp. 412-414)

${ }_{9}$ Caracterizado por autoridades de tipo personalista e por uma acentuada mercantilização dos serviços públicos ofertados pelo Estado e vendidos como mercadoria pelos seus servidores (Evans e Wolfson 1996, p. 537).
Em segundo lugar, para que essa burocracia caracterize de fato um ED ela não pode jamais insular-se, se por "insulamento" entendermos "isolamento" completo em relação à "sociedade". A burocracia do ED deve desenvolver mecanismos institucionais que lhe permitam um permanente diálogo com os setores econômicos estratégicos e organizados da sociedade em que ele atua, notadamente capital e trabalho. Ela deve ser autônoma, mas ao mesmo tempo "inserida" na sociedade. Essa autonomia inserida permite ao Estado superar seus limites institucionais e de recursos e a adotar a melhor política possível. Suas duas faces - burocracia coerente e inserção social - impedem, por um lado, que o isolamento se transforme em despotismo burocrático e descambe para o Estado predatório 9 e, por outro, que a inserção na sociedade leve o Estado a ser apropriado pelos grupos econômicos e sucumba ao clientelismo e à privatização. Com uma burocracia competente e orientada por um ethos próprio, mas ao mesmo tempo em diálogo permanente com os setores economicamente estratégicos, o ED é capaz de se orientar pela seletividade de suas decisões, isto é, definir de maneira estratégica em quais áreas irá atuar para promover o desenvolvimento, evitando gastar tempo, recursos e energia com intervenções aleatórias (Johnson 1982; Evans 1995, p. 12; Leftwich 1995, p. 408; 2000, p. 162; Evans \& Wolfson 1996, pp. 556-557). Segundo Vartianen (1999), essa inserção do Estado, nos casos analisados por ele, traduziu-se, na prática, na construção de uma estrutura corporativista de representação de interesses.

\section{III.3. A dimensão volitiva do ED}

\footnotetext{
${ }^{10}$ Segundo Woo-Cumings (1999, p. 31), referindo-se a Johnson, a "política industrial é antes de tudo uma atitude [...] e somente depois um problema de técnica, que se altera conforme as mudanças de necessidade do tempo". Conferir importância aos ideais e projetos desses agentes não significa, porém, dizer que os resultados produzidos a partir deles correspondam exatamente às suas intenções iniciais (Merton 1976; Boudon 1993)

11 A plan rationality corresponde àquilo que Clauss Offe (1982, p. 220) chamou de lógica teleológica do Estado capitalista, na qual as premissas da ação administrativa consistem na busca de resultados concretos e pré-definidos. Para tanto, cabe à administração estatal superar premissas e rotinas de ação tidas até então como válidas. 12 Este argumento também está presente na discussão feita por Johnson (1992, p. 56)
}

O que chamamos neste texto de a dimensão volitiva do ED foi particularmente enfatizada por Leftwich $(1995 ; 2000 ; 2010)$ e se compõe de três aspectos profundamente interligados.

$\mathrm{O}$ primeiro deles, e mais importante, refere-se à presença, numa dada sociedade, de uma elite modernizante disposta a industrializar e modernizar o país, disposta, para dizer como Hirschmann (1964), a tomar "decisões desenvolvimentistas" e a implementá-las de acordo com um plano ${ }^{10}$. Essa elite modernizante, portanto, deverá se dedicar à construção de um Estado que oriente suas ações econômicas por aquilo que Johnson (1982, pp. 17-21) chamou de plan rationality, em oposição à racionalidade de mercado e à racionalidade estritamente ideológica. A característica específica dessa racionalidade orientada pelo plano consiste num tipo de intervenção estatal pautada pela produção de determinados resultados. Nesse sentido, a ideia de "eficácia" (entendida como obtenção do resultado previamente definido pelo plano) predomina sobre a de "eficiência" (entendida como a melhor relação custobenefício produzida pelo empreendimento). O que importa é o resultado, ainda que ele seja produzido com alguma ineficiência, alguma externalidade negativa, como dizem os economistas ${ }^{11}$.

Essa elite modernizante não é, certamente, condição suficiente para a existência desse tipo de Estado, mas sim condição necessária, sem a qual as demais condições não poderiam se traduzir em "decisões desenvolvimentistas" automaticamente. Não basta, portanto, que todas as características institucionais e contextuais identificadas acima estejam presentes se uma sociedade não conta com um grupo social disposto a assumir politicamente a tarefa de controlar o Estado, construir suas capacidades institucionais e promover o desenvolvimento como um "projeto" político, cuja evolução dependerá muito das características desse grupo ${ }^{12}$. Como bem observa Woo-Cumings, ao comentar o livro de Johnson, a estratégia analítica fundamental quanto a esse ponto não consiste em identificar relações causais unívocas, mas em produzir "uma explicação histórica em busca do significado [...] por detrás das ações dos decisores japoneses: que circunstâncias e visões de mundo levaram aqueles 
sobre o peso do contexto internacional no desenvolvimento econômico. Ver também Hall (1986; 1993), para quem uma elite de decisores fortemente imbuída de uma ideologia econômica é um componente importante da autonomia do Estado frente aos grupos de pressão.

13 Ver também Chang (1999, p. 192-196). homens a modelar as instituições que criaram a famosa política industrial japonesa" (Woo-Cumings 1999, p. 2; sem grifos no original). Mais do que isso, como observa Kohli (1999, pp. 128-132), o estudo das características e atributos das elites estatais permitiria aos estudiosos do Estado desenvolvimentista ir além da análise das "capacidades estatais" e estudar as origens dos objetivos deste Estado. Para este autor, tais objetivos não estão "naturalmente" inscritos em qualquer estrutura institucional, mas são o fruto de escolhas conscientes feitas por atores específicos portadores de motivações para o desenvolvimento, que, por sua vez, conduzem à produção de uma estrutura institucional a serviço desses mesmos objetivos.

Assim, em segundo lugar, essa elite modernizadora deve ser capaz de iniciar e sustentar um processo de state-building que produza instituições estatais aptas a perseguir metas desenvolvimentistas. As instituições do Estado, porém, serão importantes não apenas porque produzirão decisões desenvolvimentistas, mas também porque (re)produzirão os agentes que irão operá-las, isto é, a burocracia a que nos referimos acima, ela mesma parte importante dessa elite desenvolvimentista. Desse modo, as instituições estatais irão produzir os agentes que, por sua vez, irão reproduzi-las por meio de suas práticas. Para Leftwich (1995, pp. 405-419), essa elite burocrática deve ser pequena, integrada, ainda que não monolítica, próxima do Poder Executivo, recrutada essencialmente nas estruturas burocráticas do Estado (civil e militar) e caracterizada pelo predomínio de uma burocracia econômica.

Em terceiro lugar, o eventual sucesso dessa elite modernizante em construir as instituições do ED, fazê-las funcionar de acordo com uma plan rationality orientada para a industrialização e produzir uma burocracia dotada de poder para tanto depende de sua capacidade para construir um "consenso político" em torno desse objetivo e formar aquilo que Leftwich (2010) chamou de "coalizão desenvolvimentista" ${ }^{13}$. Nesse sentido é que o desenvolvimento econômico é, segundo esse autor, um fenômeno prioritariamente político e a sua ocorrência (ou o seu fracasso) depende muito da capacidade política dessa elite modernizante forjar esse tipo de coalizão com outras elites exteriores ao Estado (econômica, sindical etc.). Essa elite cumpriria assim o papel de "agente de ligação" (biding agent), identificado por Hirschmann (1964) como essencial para qualquer projeto desenvolvimentista.

Resumindo, um Estado Desenvolvimentista é, como um tipo ideal, aquele em que uma elite política orientada por ideais desenvolvimentistas e incentivada por um contexto internacional ameaçador é capaz de forjar uma aliança política de modo a sustentar um processo de construção institucional e de formação de uma burocracia econômica que seja, ao mesmo tempo, suficientemente coesa, socialmente inserida, com autonomia e capacidade para formular e implementar uma política de industrialização que redefina, no longo prazo, a estrutura econômica de um país.

\section{O conceito e sua utilidade para a comparação entre os casos brasileiro e argentino}

Apesar de o conceito de ED ter sido originalmente formulado para entender o desenvolvimento econômico em países asiáticos, parece-nos que, como um tipo ideal, pode ser adequadamente utilizado para comparar e entender as diferenças nos processos de industrialização ocorridos no Brasil e na Argentina entre os anos de 1930 e $1966^{14}$.

${ }^{14}$ Sobre a capacidade do conceito ser aplicado a outros casos, ver Johnson (1999, p. 43).

No que se refere à dimensão contextual desse conceito, certamente nenhum desses países, no período indicado, passou pela dramática experiência de terem a sua soberania ameaçada ou efetivamente comprometida por potências externas, como foi o caso do Japão, da Coreia, da China e de Taiwan. Ambos, 
${ }^{15}$ Uma conjuntura crítica implica, primeiro, a presença de mudanças estruturais a serem enfrentadas pelos casos analisados; em segundo lugar, formas diversas, em cada caso, de reação a essas mudanças e, por fim, a produção (ou não) de legados distintos, que gerem uma sociedade significativamente diferente da anterior (Collier \& Collier 1991, p. 30).

${ }^{16}$ Sobre a natureza conservadora do golpe de 6 de setembro de 1930 na Argentina, cf. Wynia (1978, pp. 23-36), Albertini e Castiglioni (1985, pp. 3-4), Waisman (1987, pp. 130-131), Jauregui (2000, pp. 70-73), Sidicaro (2002, pp. 28-29) e Romero (2005). Sobre o movimento de 3 de outubro de 1930 no Brasil, ver Fausto (1990; 1997), Forjaz (1978), Saes (1991), Prestes (1999), Fonseca (1987) e Martins (1976).

${ }^{17}$ Quanto a este ponto, ver entrevista com Jauretche (1971, p. 84) entretanto, viveram uma "conjuntura crítica" (Collier \& Collier 1991, pp. 27-39), a crise de 1929, que os obrigou a enfrentar uma opção dramática: permanecer enquanto sociedade predominantemente agroexportadora ou trilhar o caminho da industrialização ${ }^{15}$. A essa conjuntura crítica os dois países responderam diferentemente.

A diversidade dessa resposta pode ser inicialmente apreendida a partir da natureza profundamente diferente do que foram o 1930 argentino e o 1930 brasileiro. No primeiro caso, uma reação conservadora cujo significado foi, essencialmente, a reafirmação da hegemonia política e econômica do setor agroexportador argentino; no caso brasileiro, a ascensão de uma elite política modernizante, pautada por um positivismo político, em busca de racionalidade administrativa e modernização econômica ${ }^{16}$. Dito de outra maneira, ausência de uma elite modernizante, no primeiro caso, e presença, no segundo.

Esses dois momentos políticos críticos produziram resultados muito distintos nos dois países no que diz respeito à dimensão institucional dos respectivos Estados. No caso Argentino, presenciamos a adoção, durante a chamada "Década Infame", de uma estratégia de construção institucional de agências econômicas voltas fundamentalmente para salvaguardar os interesses hegemônicos do setor agroexportador. Isso só se alterou com o golpe de 1943 e, logo depois, com a ascensão de Perón. Mas mesmo aí o que presenciamos é uma grande timidez no que diz respeito à construção de instituições estatais voltadas para a promoção da industrialização pesada e uma grande ousadia no que diz respeito à inclusão social, econômica e política da classe trabalhadora. Depois de Perón, somente o governo de Arturo Frondizi toma o desenvolvimento industrial e a ideologia econômica do desenvolvimentismo a sério, mas também aí o processo de construção institucional necessário para levar a estratégia desenvolvimentista adiante foi bastante tímido (talvez o CONADE seja a grande inovação do período) e terminou de maneira dramática com o golpe que derruba o presidente em 1962. Aliás, em entrevista, Roberto Alemann, Ministro da Fazenda do final do governo de Frondizi, revela o caráter altamente personalista do processo decisório de política econômica do governo Frondizi, centrado na pessoa do presidente e de Rogelio Frigerio (Alemann 1973, pp. 8-10). Até então, a cena política argentina teria sido dominada amplamente pela oposição entre oligarquia liberal e peronismo, sem que o desenvolvimentismo se apresentasse como alternativa politicamente significativa ${ }^{17}$.

No caso brasileiro, contrariamente, o que se inicia logo após a Revolução de 1930 é um processo de construção institucional bastante vigoroso com vistas à racionalização administrativa (cuja máxima expressão é a criação do DASP) e ao desenvolvimento econômico (como a Comissão de Similares, o CTEF, o CFCE, o CNP, a Carteira de Crédito Agrícola e Industrial etc.). Além desse processo de intensa inovação institucional, outras agências estatais previamente existentes, como o Itamaraty e o Banco do Brasil, foram postas a serviço desses dois objetivos, contribuindo para a formação de técnicos competentes dedicados a pensar a modernização econômica. Muitos dos técnicos especialistas nos mais diversos assuntos econômicos (câmbio, crédito, moeda) aprendiam suas funções por meio de uma socialização on the job e nesse processo o contato com funcionários mais experientes era fundamental. Por exemplo, em entrevista ao CPDOC, Casimiro Ribeiro, inicialmente funcionário concursado do Departamento de Estatística e Assuntos Econômicos do Banco do Brasil e, depois, na Cexim e na Sumoc, faz a seguinte observação sobre a sua relação profissional com Roberto Campos e Eugênio Gudin: "Eu poderia ficar falando horas, dando exemplos de como eles orientaram, ajudaram e estimularam toda uma nova geração de economistas, dando realmente seriedade à profissão no país, mesmo antes de ela ser regulamentada oficialmente" (Ribeiro 1982, p. 11) ${ }^{18}$. 
18 Sobre esse ponto, ver também Gouvêa (1994 cap. I).

19 Para mais informações, ver Daland (1967), Graham (1968); Baer, Kerstenetzky e Villela (1973); Fonseca (1987); Geddes (1990); Bosi (1992); Leopoldi (1992; 2000); Gouvêa (1994); Draibe (1996); Fausto (1996); Loureiro (1997).

${ }^{20}$ Para mais informações, cf. Altimir, Santamaría e Sourrouille (1966), Morales (1972), Mallon e Sourrouille (1975), Rouquié (1975), Potash (1984), Frigerio (1985), Belini (2001), Sidicaro (2002), Donghi (2004) e Romero (2005; 2006). Para uma comparação entre Brasil e Argentina, ver Fausto e Devoto (2004) e Sikkink (1991)

21 Sobre a fragilidade ou mesmo ausência de mecanismos de representação empresarial na Argentina, ver Mallon e Sourrouille (1975, pp. 3 e 154), Wynia (1978, pp. 15 e 54-79), Brennan (1997) e Jauregui (2000; 2004). Sobre o caso brasileiro, ver Diniz (1978), Leopoldi (1992; 2000) e Jauregui $(2000 ; 2004)$.
Essa tendência será acentuada nas décadas seguintes, com o surgimento das instituições clássicas do desenvolvimentismo brasileiro, notadamente a Assessoria Econômica da Presidência da República, o BNDE e os Grupos Executivos. Nessas instituições se materializou e sobreviveu entre os anos de 1930 a 1964 a ideologia econômica do desenvolvimentismo. Ainda do ponto de vista institucional, a literatura revela que o Brasil $^{19}$ foi também mais bem sucedido do que a Argentina ${ }^{20}$ no que diz respeito à construção de uma estrutura corporativa de representação de interesse, o que garantiu um diálogo mais profícuo entre a presidência e a burocracia econômica, por um lado, e setores importantes do empresariado, por outro ${ }^{21}$.

As diferenças rapidamente descritas acima podem ser atribuídas, em grande parte, às singularidades relativas à dimensão volitiva do $\mathrm{ED}$, isto é, à presença, no caso brasileiro, de uma elite modernizante disposta a pensar a industrialização não apenas como uma resposta pragmática aos choques externos, mas como um novo caminho a ser trilhado e para o qual uma estratégia política e institucional deveria ser pensada a médio e longo prazo. Nesse sentido, o "positivismo político", identificado por Fonseca (1987), jogou papel central como visão de mundo a orientar o sentido da ação dos decisores brasileiros e, como mostra Martins (1976), a consolidar uma aliança entre a burocracia civil e militar que sustentaria politicamente esse projeto ao longo dos anos aqui analisados.

Assim, como revela Fonseca (1987), o positivismo dos revolucionários de 1930 no Brasil funciona como uma espécie de desenvolvimentismo avant la lettre que fornecerá às posições teóricas da Cepal um terreno fértil onde florescer. Ao contrário, na Argentina, a permanência do liberalismo como ideologia econômica hegemônica durante a maior parte de sua história e a sua eventual substituição por um intervencionismo de cunho mais social que propriamente econômico, durante o peronismo, conferiram ao desenvolvimentismo cepalino uma posição absolutamente débil no cenário ideológico argentino quando comparado com o Brasileiro, como mostra muito bem Sikkink (1991).

Todo esse processo superficialmente resumido acima teve como efeito no Brasil (mas não na Argentina) a produção de um corpo de agentes estatais que viria a ser responsável pela condução das agências econômicas do ED brasileiro ao longo do período. Aquela elite modernizante que assume o poder a partir de 1930 promove um processo de construção institucional cujo efeito é a formação, no interior dessas agências estatais, de um corpo estável de burocratas econômicos, majoritariamente recrutados no setor público e portadores de um ethos desenvolvimentista. A essa burocracia econômica caberá o papel de, a despeito da crônica instabilidade política brasileira durante o período, garantir a permanência das agências econômicas do Estado brasileiro e do parâmetro de política econômica que essas agências geraram ao longo do período: o desenvolvimentismo (Leff 1968). Presenciamos, assim, um processo de construção institucional que produz agentes com um ethos específico, que, por sua vez, reproduzem, ao longo do tempo, as instituições que os formaram e, consequentemente, instauram um padrão de política econômica.

O problema da estabilidade da burocracia econômica é, a nosso ver, fundamental para entender a diferença entre Brasil e Argentina no que diz respeito à continuidade de uma política favorável à industrialização. Grande parte da literatura argentina tende a explicar o precário desenvolvimento industrial desse país em função de sua crônica instabilidade política. No entanto, esse é um problema que afligia aos dois países. Brasil e Argentina passaram, entre 1930 e 1966, por número idêntico de golpes de Estado: 1930, 1943, 1955, 1962 e 1966, na Argentina, e 1930, 1937, 1945, $1954^{22}$ e 1964 no Brasil. Durante 36 anos, a 
${ }^{22}$ Esses dados foram retirados de fontes da internet referenciadas no final deste artigo. Ver também Sábato (1988, p. 246). Sobre a instabilidade de presidentes, ministros e presidentes do Banco Central argentino, de 1946 a 1976, ver Pablo (1980, pp. 31-41; 1989, pp. 131-32). Ver também Pablo (1977) sobre a avaliação que os próprios economistas fazem sobre a questão da instabilidade política.

${ }^{23}$ Essa ideia foi originalmente defendida por Martins (1976, pp. 141-143) e por Leff, 1968. ${ }^{24}$ Sobre a definição de prosopografia, ver Stone (1972, p. 107).

${ }^{25}$ Para informações detalhadas sobre o Banco e os dados, ver Perissinotto (2012).
Argentina teve 13 presidentes, com média de 2,7 anos para cada presidente; durante 34 anos, o Brasil teve 11 presidentes (contando os interinos e excluindo a Junta Governativa Provisória de 1930), isto é, 3,09 anos para cada presidente. Durante o mesmo período, a Argentina teve 31 ministros da Economia, uma média de 1,16 ano por ministro; o Brasil, por sua vez, teve 25 ministros (45 se contarmos os interinos), uma média de 1,36 ano por ministro $(0,75$ se contarmos os interinos). Como se pode ver, a instabilidade política é um traço comum a ambos os países. A diferença é que se desviarmos o nosso olhar da macropolítica para o nível menos visível da administração estatal, veremos que o Brasil contava com a presença estável de uma burocracia que conferiu continuidade à política econômica a despeito das mudanças contínuas na cena política ${ }^{23}$.

Um estudo prosoprográfico dessa burocracia econômica brasileira ${ }^{24}$ revela algumas características importantes quanto à sua formação escolar, à sua carreira e à sua ideologia econômica. Os dados foram coletados a partir de uma leitura sistemática da literatura brasileira sobre o período em questão. Essa leitura nos permitiu identificar as principais agências econômicas do Estado brasileiro e alguns indivíduos que aí atuaram. Esse procedimento gerou um universo de 123 indivíduos entre os anos de 1930 e 1964. Em seguida, fizemos uma prosopografia desses indivíduos. Dos 123 nomes identificados inicialmente, conseguimos informações suficientes para apenas 82 deles $(66,6 \%)$. As informações foram retiradas de várias fontes, mas principalmente de Dicionário Histórico Biográfico Brasileiro do Centro de Pesquisa e Documentação da Fundação Getúlio Vargas (versão online) ${ }^{25}$.

No que diz respeito à formação escolar desse grupo, os dados, como sempre na história do recrutamento das elites estatais brasileiras, mostram o Direito mais uma vez se constituindo como o mais importante "viveiro" (Offerlé 1999) de onde se recruta os agentes da burocracia econômica entre 1930 e 1964, com quase $38 \%$ dos casos. Mas há uma diferença importante quanto a esse ponto. O capital cultural e simbólico expresso na condição de bacharel representará, num primeiro momento, um facilitador do acesso a determinadas posições na burocracia. Mas, como mostra amplamente Gouvêa (1994, cap. I), a trajetória desses indivíduos no interior das agências econômicas do Estado possibilitará outro processo de formação, em que o conhecimento original, o Direito, tende a se converter em expertise na área econômica. Talvez os dois casos mais paradigmáticos nesse sentido sejam os de Octávio Gouvêa de Bulhões, formado pela Faculdade de Direito do Rio de Janeiro, e depois autoridade econômica amplamente reconhecida, e de Rômulo de Almeida, formado pela Faculdade de Direito da Bahia, líder da Assessoria de Vargas e nome fundamental na elaboração do projeto da Petrobrás.

Os dados também revelam a importância da formação em engenharia, com $35 \%$ dos casos. Entre os engenheiros predominam os militares e os civis cuja primeira ocupação profissional foi algum tipo de atuação técnica. Parte significativa dos militares irá atuar nos conselhos técnicos da área de petróleo e siderurgia. Entre os civis, muito deles irão reconverter sua condição de engenheiro para o ramo da economia, uma expertise cada vez demandada pelos órgãos técnicos do Estado, à medida que a intervenção estatal na organização do mundo econômico também aumentava. Segundo Leff (1968, p. 146 e nota 24), os engenheiros exerceram importante papel no processo decisório de política econômica por três razões: (i) tinham capacidade de lidar com os aspectos quantitativos do processo; (ii) inexistência de escolas de formação de economistas até os anos 1940; (iii) as escolas de engenharia no Brasil sempre contemplaram em alguma medida a ciência econômica nos seus currículos e, além disso, temas econômicos nacionais eram sempre discutidos nas suas associações profissionais. Não por outra razão, a formação em economia, que passa a existir no Brasil somente no final dos anos 1930, ocupa a terceira 
${ }^{26}$ Os dados sobre ideologia econômica referem-se apenas aos indivíduos para os quais obtemos informações sobre este assunto, isto é, 51 dos 82 . Sobre o termo "ideologia integradora", cf. Leff (1968, pp. 128 e 139-153). Sobre o papel da ideologia econômica no Estado japonês, ver Johnson (1982, p. 304). Sobre a importância da ideologia econômica na conformação da política econômica na Grã-Bretanha e na França, ver Hall (1986).

27 Para um exemplo contundente da atuação política dos técnicos, ver o relato do mesmo Ribeiro (1982, p. pp. 21-26) sobre o processo decisório da Reforma Tarifária de 1957.

${ }^{28}$ Esses termos foram inspirados na tipologia de Bielschovisky (2000) sobre o pensamento econômico no período.
29 São eles: Cleantho de Paiva Leite, Roberto de Oliveira posição, depois do direito e da engenharia, com $10 \%$ dos casos em que o predomínio de civis é absoluto. Entre os formados em economia, 87,5\% tiveram como primeira ocupação profissional uma atuação técnica em órgãos privados ou públicos, como, por exemplo, funcionário do Itamaraty, funcionário do Banco do Brasil, membro do Conselho Nacional de Águas e Energia, assessor técnico do governo brasileiro ou assessor do departamento econômico da Confederação Nacional da Indústria.

Quanto à sua carreira, em termos gerais, os dados revelam um grupo cujos membros têm uma carreira longa $(52,4 \%$ dos agentes têm entre 30 e 50 anos de carreira integral e nenhum deles tem menos de 10 anos de atividade profissional até 1964), que se desenvolve majoritariamente em funções públicas (de uma média de 7,5 posições ocupadas pelos indivíduos analisados, 4,6 são de funções públicas), em grande parte funcionários de carreira $(47,6 \%$, se somarmos funcionários civis e militares), com perfil predominantemente técnico (62,2\% se somarmos os indivíduos de carreira técnica com os técnicos-políticos), circulam pouco entre os universos político e empresarial (46,3\% dos agentes não executam nenhum movimento entre os setores público e privado e $34,1 \%$ executam apenas um) e, por fim, estão, em sua maioria, unidos em torno de uma "ideologia integradora", que é o desenvolvimentismo (76,5\% professam algum tipo de desenvolvimentismo $)^{26}$.

Os técnicos-políticos, aliás, são oriundos preferencialmente de funções públicas, mas atuam politicamente na defesa de seus projetos (Schneider 1991). Essa mistura de técnica e política não é uma característica apenas de indivíduos. Algumas agências cumpriam também essa dupla função. É o caso do Departamento de Estatística e Estudos Econômicos do Banco do Brasil durante o Estado Novo, cujo relatório cumpria uma função política, enquanto a análise técnica ficava restrita ao funcionamento interno da agência (Ribeiro 1982, p. 9$)^{27}$.

No que se refere à relação entre ideologia econômica e tipo de carreira, os nossos dados mostram que os desenvolvimentistas, sejam nacionalistas, sejam $\operatorname{cosmopolitas}^{28}$, são sistematicamente maioria nas carreiras de natureza pública e técnica (entre os militares eles perfazem 100\%; entre os técnicos civis, 70\%, e entre os técnicos-políticos, mais de $90 \%$ ); os liberais, ao contrário, estão em maior número nas carreiras privadas e políticas (perfazem $62,5 \%$ entre os que têm carreira político-empresarial).

Quanto ao lugar desses agentes no interior do aparelho econômico de Estado, podemos ver que os desenvolvimentistas cosmopolitas se concentram em agências como o Banco do Brasil, o Itamaraty, o Conselho Técnico de Economia e Finanças e a Coordenação de Mobilização Econômica. Como se sabe, os cosmopolitas são defensores da intervenção estatal como indutor do desenvolvimento, mas não recusam a participação do capital privado, sendo inclusive bastante entusiasmados em relação à participação do capital estrangeiro nesse processo. Nesse sentido, o Itamaraty é um locus "natural" de atração para esse tipo de orientação ideológica. O Banco do Brasil, entidade que ocupa papel fundamental no desenvolvimento econômico enquanto agência de concessão de crédito, especialmente antes da criação do BNDE, é outro local institucional a ser ocupado por aqueles que, de alguma forma, pretendem participar das decisões de política econômica.

Os desenvolvimentistas nacionalistas concentram-se basicamente em duas agências. A primeira, amplamente dominada por militares, é o CNP (todos os membros desta agência são desenvolvimentistas); a segunda, amplamente dominada por civis (dos nove membros identificados por nós, nenhum é militar) ${ }^{29}$, é a AEPR (em que oito dos nove membros identificados também são desenvolvimentistas). O BNDE, por sua vez, é a instituição em que cosmo- 
Campos, Lourival Fontes, Válder Lima Sarmanho (sem informação sobre ideologia econômica), Jesus Soares Pereira, Glycon de Paiva Teixeira, Inácio Rangel, Rômulo Barreto de Almeida e Tomás Pompeu Aciolly Borges.

30 "Nesse período [de criação da Sumoc], o déficit orçamentário, as emissões de papel moeda e os desequilíbrios na balança comercial fizeram com que se chamasse Octávio Gouvêa de Bulhões como assessor, um homem conhecido por suas posições monetaristas" (Gouvêa 1994, p. 109).

${ }^{31}$ Entre os nomes citados pela literatura estão: Abraham Gerest, Alizon Garcia, Edmundo G. Gagneux, Francisco Croire, Julio Broide, Max Alemann, René Berger (Dosman 2011). Ver também entrevista com Pinedo (1973). politas e nacionalistas, por assim dizer, deixam suas diferenças de lado a fim de dar vida a uma instituição que ambos consideram fundamental para o desenvolvimento econômico do país.

Os liberais se concentram no Banco do Brasil, na SUMOC, na FGV e no CNE. Banco do Brasil e SUMOC, como já observamos, são agências fundamentais na definição da política monetária, pilar essencial, estratégico e prioritário da política econômica na perspectiva liberal ${ }^{30}$. A FGV será uma instituição fundamental na produção de dados macroeconômicos para formular a política monetária, notadamente dados sobre a inflação e sobre as contas nacionais. Por fim, o CNE, cidadela liberal segundo Bielschovsky (2000, pp. 341 e 368), foi criado em 1946, implantado definitivamente em 1949, como contraponto liberal às orientações desenvolvimentistas do CFCE (Wirth 1970, p. 103).

A hegemonia liberal só ocorre mesmo no interior do CNE (cinco dos seis indivíduos identificados como membros desta instituição são liberais). Em todas as outras instituições, eles dividem espaço com os demais grupos ideológicos. Desse modo, por mais que os liberais controlem, em detrimento dos "estruturalistas", o processo de institucionalização da economia enquanto disciplina acadêmica e, por conseguinte, assumam as posições dominantes no interior desse campo, como mostrou Loureiro (1994, pp. 44-50), no interior do aparelho estatal parecem ocupar posição francamente subordinada. O caso da Sumoc é, nesse sentido, ilustrativo. Um dos lugares institucionais mais importantes para os liberais, a SUMOC foi, desde sua criação até 1965, quando deixou de existir, uma instituição que nunca obteve aquilo que era o maior desejo dos liberais, a saber, o controle sobre a expansão da base monetária como efeito da política econômica desenvolvimentista. Segundo um dos seus mais destacados funcionários:

"Na prática, a Sumoc ficou como mero órgão de fiscalização, de inspetoria e de estudos econômicos, ou um pouco mais do que isto, encarregada da autorização de cartas patentes de bancos e instituições financeiras. Não era mais do que isto. Os depósitos compulsórios, que deviam ir para uma caixa especial da Sumoc, jamais o foram... Do ponto de vista financeiro, a Sumoc virou uma espécie de apêndice do Banco do Brasil”' (Ribeiro 1982, p. 12).

É muito difícil repetir esse mesmo procedimento de pesquisa para o caso argentino, não apenas pelos obstáculos referentes à coleta de informações sobre essa burocracia econômica de segundo escalão, mas fundamentalmente porque esse grupo, como corpo burocrático estável, encontrava-se ausente do Estado argentino. É verdade que logo após 1930, graças ao empenho de Federico Pinedo, Raúl Prebisch e Ernesto Malaccorto, a Argentina deu início a um intenso processo de inovação institucional que redundaria na formação de uma competente equipe técnica na área de economia e na criação do Banco Central Argentino $^{31}$.

No entanto, duas informações são importantes aqui. Primeiramente, esse processo de construção institucional não era voltado para a instalação de agências estatais voltadas para pensar a industrialização como alternativa à economia agroexportadora, como no Brasil. Como mostra amplamente a literatura, logo após 1930, as agências econômicas criadas na Argentina eram voltadas essencialmente para a proteção da atividade agroexportadora e aquelas agências criadas para o fomento da indústria, como a Comissão de Fomento Industrial, não saíram do papel. O próprio Banco Central se limitava a uma intervenção no âmbito da política monetária. Mesmo depois de Perón, não se inovou significativamente nesse período. Em segundo lugar, a competente equipe técnica criada por Prebisch foi totalmente desfeita com a ascensão de Perón. Um depoimento dado por Celso Furtado é contundente a esse respeito. Segundo o economista brasileiro, Prebisch dizia: 
${ }^{32}$ Ver também Jauretche (1971), Morales (1972), Dirié (1981) e Sidicaro (2002). Quanto ao depoimento de Prebisch, é preciso levar em consideração, é claro, o conhecido antiperonismo do famoso economista argentino.

\section{Conclusões}

\footnotetext{
${ }^{33}$ Não se trata, é claro, de transformar esse fator na única causa a explicar tal diferença. Há, certamente, outras. Por exemplo, alguns autores sugerem diferenças importantes no que diz respeito à fronteira agrícola, à estrutura do mercado de trabalho ou ao desempenho do setor exportador da crise de 1929. Cf., por exemplo, Baer (1965), Sheahan (1982), Di Tella (1986), Bulmer-Thomas (1998) e Thorp (1998)
}

"Vargas supo formar cuadros, dio estructura moderna al Estado brasileño. Vea a Perón: dispersó con un gesto un equipo que me costó diez años formar'. Decir eso debía dolerle. El equipo al que se refería había dado a la Argentina un avance quilométrico en la investigación económica en América Latina, y había hecho del Banco Central una institución admirada internacionalmente" (Furtado apud Donghi 2004, p. 141, nota 5) ${ }^{32}$.

No entanto, o peronismo não se constitui na única fonte de instabilidade administrativa. Os relatos de Alfredo Gomez Morales, figura de proa da equipe econômica durante os anos 1945-1955, também revelam a instabilidade burocrática criada pela "Revolução Libertadora". Referindo-se ao caso da liquidação da Direción Nacional de las Industrias del Estado (DINIE), Morales observa como ali, por obra dele, formou-se um corpo de funcionários estatais tecnicamente competentes, muito diferentes dos "burocratas puros" que dominavam o Estado argentino, e como, com a derrocada de Perón, não só as empresas da DINIE foram liquidadas por puro dogmatismo econômico, como houve também dispersão desse corpo de funcionários. Segundo ele, "se havia formado um pessoal de alto nível, extraordinariamente eficaz. Pois eu havia levado os melhores elementos da Dirección de los Réditos, incorporamo-los como auditores das empresas, mantivemos nas empresas todos os funcionários do velho sistema. Ou seja, procedíamos com um critério completamente alheio à politicagem. Essa é uma das coisas que lamento, porque foi uma experiência séria, muito bem feita e que em outros países foi utilizada com grande inteligência" (Morales 1972, p. 34).

Essa, portanto, parece-nos ser uma diferença fundamental para explicar o melhor desempenho brasileiro no que diz respeito ao processo de industrialização. No caso do Brasil encontramos uma elite modernizante que assume o poder político depois de 1930 e é bem sucedida em criar um corpo estável de burocratas econômicos orientados pela ideologia do desenvolvimentismo. Como dissemos antes, esta burocracia estável funcionava, no caso brasileiro, como uma espécie de anteparo a proteger a gestão da economia contra a crônica instabilidade política, anteparo este ausente do Estado argentino ${ }^{33}$.

Acreditamos que o conceito de Estado Desenvolvimentista tem vantagens teóricas, temáticas e práticas que justificam o seu uso para casos geograficamente distantes daqueles para os quais foi originalmente pensado.

A nosso ver, a grande vantagem teórica do conceito reside no fato de ter sido formulado a partir de análises comparativas. Ainda que, no seu início, o conceito tenha surgido da análise aprofundada de um único caso, o estudo do Japão feito por Chalmers Johnson, pesquisas subsequentes adquiriram uma perspectiva claramente comparativa e, a partir dela, pôde-se perceber a existência de traços contextuais, institucionais e volitivos recorrentes nos Estados do sudeste e do leste asiáticos e o vínculo desses traços com processos de desenvolvimento econômico acelerado.

Nesse sentido, o conceito de ED representou um ganho teórico na medida em que a comparação histórica permitiu alguma generalização acerca desse fenômeno e o transformou em instrumento heurístico passível de ser aplicado a outros casos de países periféricos que chegaram tardiamente à industrialização. Tornou-se, assim, um típico conceito middle range, isto é, forjado por meio de estudos comparativos em uma área específica de pesquisa e voltado para a análise de contextos relativamente homogêneos (Schneider 1999, p. 279, nota 8). A presença ou ausência dos traços contextuais, institucionais e volitivos identificados pelo conceito de ED, generalizáveis em alguma medida a partir da 
${ }^{34} \mathrm{Na}$ literatura é possível encontrar maneiras diferentes de sistematizar o conceito e que se sobrepõem à apresentada neste artigo. Ver, por exemplo, Chang (1999), Loriaux 1999 e Woo-Cumings (1999). Acreditamos que a utilidade de nossa formulação reside tanto em contemplar as dimensões encontradas nesses outros autores, como também em insitir nas "motivações típicas" que caracterizam os atores estatais na construção de um ED, sem as quais qualquer tipo ideal ficaria incompleto. comparação histórica, permitem entender porque alguns países tardios são mais bem sucedidos que outros no processo de desenvolvimento econômico. Como tentamos mostrar neste texto, o conceito de ED permite revelar as similaridades e diferenças, as ausências e presenças que levam alguns países periféricos e tardios a um processo de industrialização mais profundo do que outros, a despeito de um início desvantajoso do ponto de vista econômico, como é o caso do Brasil em relação à Argentina.

O conceito de ED traz consigo também uma grande vantagem temática para o estudo dos processos de desenvolvimento em países tardios, pois coloca no centro de suas preocupações a necessidade de se fazer uma sociologia das elites estatais para um pleno entendimento do processo de industrialização. O elemento volitivo a que nos referimos anteriormente aponta exatamente para a presença de um agente político disposto e capaz de incorporar um projeto de desenvolvimento e sustentá-lo ao longo do tempo e, desse modo, permite superar visões estritamente econômicas ou institucionais dos mesmos. Nesse sentido, a utilidade do conceito reside, antes de tudo, no fato de ter sido pensado como um tipo ideal weberiano, isto é, obrigado a contemplar, além das dimensões contextuais e institucionais, as dimensões volitivas que permitam capturar as motivações típicas que caracterizam uma atitude desenvolvimentista por parte da elite estatal. No entanto, tal vantagem não vem acompanhada de uma visão excessivamente voluntarista desse processo, já que o conceito indica que variáveis de tipo contextual são limites importantes à ação desse grupo ${ }^{34}$. Ao mesmo tempo, porém, condições objetivas favoráveis não se traduzem automaticamente em desenvolvimento econômico sem a presença de um grupo disposto a direcionar tais condições para a industrialização. Dito de outra forma, o conceito de ED introduz na explicação a dimensão da ação e, por conseguinte, dos grupos sociais dispostos a realizá-la, de seus atributos e motivações. A comparação entre Brasil e Argentina sugere que nesse ponto reside uma diferença fundamental entre os dois países que permite entender o melhor desempenho da industrialização brasileira.

Estre trabalho sustentou a hipótese de que um grupo com essas características estava disponível na sociedade brasileira, tendo exercido papel fundamental na Revolução de 1930, mas se encontrava ausente da sociedade argentina. Essa diferença afetou, de maneira fundamental, o desenvolvimento econômico posterior de ambos os países. No caso brasileiro, gerou um processo de construção institucional que, por sua vez, traduziu-se na produção de uma burocracia econômica estável que sustentou a ideologia econômica do desenvolvimentismo dentro do Estado brasileiro entre os anos 1930 e 1964; no caso argentino, ao contrário, inviabilizou a ocorrência de um processo semelhante, comprometendo a estabilidade e continuidade das políticas econômicas. Portanto, a presença/ausência dessa elite modernizante e dessa burocracia disposta a promover o desenvolvimento parece ser um fator indispensável para entender as singularidades do processo de desenvolvimento em ambos os países. Certamente, não é o único a explicar o melhor desempenho brasileiro nesse aspecto, mas é inegavelmente central e certamente mais importante que a famigerada instabilidade política, cronicamente presente tanto lá como cá.

Por fim, o conceito de ED sugere evidentes implicações para o debate político. Ao revelar, pela comparação histórica de processos de desenvolvimento em países tardios diversos, que a presença de uma elite modernizante capaz de instituir um processo de construção institucional e de gerar agentes estatais portadores de um ethos desenvolvimentista constitui-se numa dimensão essencial da industrialização tardia, o conceito mostra que a formação de uma elite portadora desses atributos é um problema político estratégico. 
Esse ponto é particularmente importante para o caso brasileiro, quando parte da literatura tem se voltado exatamente para a discussão do que se convencionou chamar de "neodesenvolvimentismo". Mais uma vez, essa literatura parece enfatizar os condicionamentos econômicos desse suposto novo desenvolvimento. Quando vai além deles, limita-se a falar, em termos gerais, de condições institucionais e políticas propícias, mas sem tomar a sério o papel central das elites estatais e de suas capacidades políticas nesse processo. Os estudos sobre os EDs ao redor do mundo revelam que antes de analisar as medidas econômicas "recomendáveis", antes de propugnar reformas políticas deste ou daquele tipo, seria preciso questionar-se sobre a existência ou não de um grupo disposto a encarnar um projeto de desenvolvimento industrial e de construir uma "coalizão desenvolvimentista" capaz de levá-lo adiante. Esse nos parece ser um problema central num país em que a ideia de um "projeto nacional" despareceu do cenário político.

Renato Perissinotto (monseff@gmail.com) é Doutor em Ciência Política pela Universidade Estadual de Campinas (Unicamp), professor dos programas de pós-graduação em Sociologia e Ciência Política da Universidade Federal do Paraná (UFPR) e editor-chefe da Revista de Sociologia e Política.

\section{Referências}

Albertini, J.; Castiglioni, F.M. 1985. Política e ideologia em la industrialización argentina. Boletín Informativo Techint, 239. Disponível em: http://fundacionregional.com.ar/download/politica_e_ideologia_en_la_industrializacion_argentina.pdf. Acesso em: 20 nov 2014.

Altimir, O.; Santamaría, H.; Sourrouille, J. 1966. Los instrumentos de promocíon industrial en la postguerra. Desarrollo Económico, 6(21), pp. 89-144.

Baer, W. 1965. Industrialization and Economic Development in Brazil. Homewood: Richard D. Irwin.

Baer, W.; Kerstenetzky, I.; Villela, A.V. 1973. The Changing Role of the State in the Brazilian Economy. World Development, 1(11), pp. 23-34.

Balestro, M.V. 2012. Instituições do Estado desenvolvimentista na América Latina no contexto pós-neoliberal: os casos do Brasil e Argentina em perspectiva comparada. In $36^{\circ}$ Encontro Anual da Anpocs. Caxambu.

Belini, C. 2001. DI.N.I.E y los límites de La política industrial peronista. Desarrollo Económico, 41(161), pp. 97-119.

Bendix, R. 1963. Concepts and Generalizations in Comparative Sociological Studies. American Sociological Review, 28, pp. 532-539.

1996. Construção nacional e cidadania. São Paulo: Edusp.

Bielschowsky, R. 2000. O pensamento econômico brasileiro. O ciclo ideológico do desenvolvimentismo. Rio de Janeiro: Contraponto.

Boschi, R., ed. 2011. Variedades de capitalismo, política e desenvolvimento na América Latina. Belo Horizonte: Editora da UFMG.

Bosi, A. 1992. A arqueologia do Estado-providência: sobre um enxerto de ideias de longa duração. In , ed. Dialética da colonização. São Paulo: Companhia das Letras.

Boudon, R. 1993. Effets pervers et ordre social. Paris: Quadrige/Presse Universitaire de France.

Brennann, J.P. 1997. Industriales y 'bolicheros': la actividad económica y la alianza populista peronista, 1943-1976. Boletín del Instituto de Historia Argentina y Americana Dr. Emilio Ravignani. Tercera serie, n. 15, 1er semestre de 1997.

Bulmer-Thomas, V. 1998. The Latin American Economies, 1929-1939. In L. Bethell, ed. Latin America. Economy and Society since 1930. Cambridge, UK: Cambridge University Press.

Chang, H-J. 1999. The Economic Theory of the Developmental State. In M. Woo-Cumings, ed. The Developmental State. Ithaca/London: Cornell University Press.

Collier, R.B.; Collier, D. 1991. Shaping the Political Arena. Princeton: Princeton University Press.

Cortés-Conde, R. 2009. The Political Economy of Argentina in the Twentieth Century. Cambridge, UK: Cambridge University Press.

Cumings, B. 1999. Webs with no Spiders, Spiders with no Webs: The genealogy of the developmental state. In M. Woo-Cumings, ed. The Developmental State. Ithaca/London: Cornell University Press.

Daland, R.T. 1967. Brazilian Planning. Development, Politics, and Administration. North Carolina: The University of North Caroline Press.

Diniz, E. 1978. Empresário, Estado e capitalismo no Brasil: 1930/1945. Rio de Janeiro: Paz e Terra.

Dirié, C. 1981. El Estado intervencionista en la Argentina. Disponível em: http://www.amersur.org.ar/SocEdyTrab/EstadoIntervencionista.htm. Acesso em: 20 nov 2014. 
Di Tella, G. 1986. Economic Controversies in Argentina from the 1920s to the 1940s. In G. Di Tella; D.C.M. Plat, eds. The Political Economy of Argentina, 1880-1946. Oxford: MacMillan.

Donghi, T.H. 2004. La República imposible (1930-1945). Buenos Aires: Ariel Historia.

Dorfmann, A. 1983. Cincuenta años de industrialización en la Argentina (1930-1980). Buenos Aires: Ediciones Solar.

Dosman, E.J. 2011. Raúl Prebisch (1901-1986). A construção da América Latina e do Terceiro Mundo. Rio de Janeiro: Contraponto.

Draibe, S. 1996. Rumos e metamorfoses. Estado e industrialização no Brasil: 1930-1960. Rio de Janeiro: Paz e Terra.

Evans, P. 1995. Embedded Autonomy. States and Industrial Transformation. Princeton: Princeton University Press.

Evans, P.; Stephens, J.D. 1988. Studying Development since the Sixties: The emergence of a New Comparative Political Economy. Theory and Society, 17(5), pp. 713-745.

Evans, P.; Wolfson, L. 1996. El Estado como problema y como solución. Desarrollo Económico, 35(140), pp. $529-562$.

Fajnzylber F. 1983. La industrialización trunca de América Latina. México: Editorial Nueva Imagen.

Fausto, B. 1990. A crise nos anos vinte e a Revolução de 1930. In ed. História Geral da Civilização Brasileira. O Brasil Republicano (Sociedade e Instituições, 1889-1930). Rio de Janeiro: Difel.

1996. História do Brasil. $4^{\text {a }}$ Ed. São Paulo: Edusp.

1997. A Revolução de 1930: historiografia e história. São Paulo: Companhia das Letras.

Fausto, B.; Devoto, F.J. 2004. Brasil e Argentina: um ensaio de histórica comparada (1850-2002). São Paulo: Editora 34.

Ffrench-Davis, R.; Muñoz O.; Palma, J.G. 1998. The Latin American Economies, 1950-1990. In L. Bethell, ed. Latin America. Economy and Society since 1930. Cambridge, UK: Cambridge University Press.

Fonseca, P.C.D. 1987. Vargas: o capitalismo em construção (1906-1954). São Paulo: Editora Brasiliense.

Forjaz, M.C.S. 1978. Tenentismo e Aliança Liberal (1927-1930). São Paulo: Polis.

Frigerio, R. 1990. Rogerio Frigerio. In G. Di Tella; C.R. Braun, eds. Argentina, 1946-83: The Economic Ministers Speak. London/Oxford: MacMillan/St. Antony's College.

Geddes, B. 1990. State Autonomy in Brazil, 1930-1964. Comparative Politics, 22(2), pp. 217-235.

Gerschenkron, A. 1976 [1962]. Economic Backwardness in Historical Perspective. A Book of Essays. Cambridge, MA: Harvard University Press.

Gouvêa, G.P. 1994. Burocracia e elites burocráticas no Brasil. São Paulo: Editora Paulicéia.

Graham, L.S. 1968. Civil Service Reform in Brazil. Principles vs. Practice. Austin: University of Texas Press.

Hall, P.A. 1986. Governing the Economy. The Politics of State Intervention in Britain and France. Oxford: Oxford University Press.

1993. Policy Paradigms, Social Learning, and the State: The Case of Economic Policymaking in Britain. Comparative Politics, 25(3), pp. 275-296.

Hirschmann, A.O. 1964. [1958]. The Strategy of Economic Development. New Haven: Yale University Press.

Ianoni, M. 2013. Teoria do estado desenvolvimentista: uma revisão da literatura. In $37^{\circ}$ Encontro Anual da Anpocs. Caxambu.

Jauregui A.P. 2000. La regulación econômica y la representación corporativa en la Argentina y el Brasil. Revista de Sociologia e Política, 14, pp. 61-75.

2004. Brasil y Argentina: los empresários industriales - 1920-1955. Buenos Aires: Imago Mundi.

Johnson, C. 1982. MITI and the Japanese Miracle. The Growth of Industrial Policy, 1925-1975. Stanford: Stanford University Press.

1999. The Developmental State: The Odyssey of a Concept. In M. Woo-Cumings, ed. The Developmental State. Ithaca/London: Cornell University Press.

Kiely, R. 1998. Industrialization and Development. London: Arrowhead Books.

Kohli, A. 1999. Where Do High-Growth Political Economies Come From? The Japanese lineage of Korea's 'Developmental State'. In M. Woo-Cumings, ed. The Developmental State. Ithaca/London: Cornell University Press.

Kohli, A. 2007. State Directed Development. Political power and industrialization in the global periphery. Cambridge, UK: Cambridge University Press.

Leff, N. 1968. Economic Policy-Making and Development in Brazil, 1947-1964. New York: John Wiley \& Sons.

Leftwich, A. 1995. Bringing Politics Back In: Towards a model of the Developmental State. The Journal of Developmental Studies, 31(3), pp. 400-427. 2000. States of Development. On the Primacy of Politics in Development. Cambridge, UK: Polity Press.

2010. Beyond Institutions: Rethinking the Role of leaders, elites and coalitions in the institutional formation of Developmental States and strategies. Forum for Developmental Studies, 37(1), pp. 93-111.

Leopoldi, M.A.P. 1992. Burocracia, empresariado e arenas decisórias estratégicas: trajetórias do neocorporativismo no Brasil (1939-1955). Ciências Sociais Hoje, pp. 74-101.

.2000. Política e interesses na industrialização brasileira. As associações industriais, a política econômica e o Estado. Rio de Janeiro: Paz e Terra.

Loriaux, M. 1999. The French Developmental State as Mith and Moral Ambition. In M. Woo-Cumings, ed. The Developmental State. Ithaca/London: Cornell University Press.

Loureiro, M.R. 1997. Os economistas no governo. Gestão econômica e democracia. Rio de Janeiro: Fundação Getúlio Vargas. 
Mallon, R.D.; Sourrouille, J.V. 1975. Economic Policymaking in a Conflictive Society: The Argentine Case. Cambridge, MA: Harvard University Press.

Martins L. 1976. Pouvoir et développement économique. Formation et evolution des structures politiques au Brésil. Paris: Éditions Anthropos.

Merton, R.K. 1976. As conseqüências não-antecipadas da ação social. In A ambivalência sociológica. Rio de Janeiro: Zahar Editora.

Offe, C. 1982. Critérios de racionalidade e problemas funcionais da ação político-administrativa. In Problemas estruturais do Estado capitalista. Rio de Janeiro: Tempo Brasileiro.

Offerlé, M., ed. 1999. La profession politique (XIXe-XXe siècles). Paris: Éditions Belin.

Pablo, J.C. 1977. Los economistas y la economía Argentina. Buenos Aires: Ediciones Macchi. 1980. La economía que yo hice. Buenos Aires: Ediciones El Cronista Comercial.

1989. Economic Policy without Political Context: Guido, 1962-3. In G. Di Tella.; R. Dornbusch, eds. The Political Economy of Argentina, 1946-83. London: MacMillan Press.

Perissinotto, R. 2012. Burocracia econômica e industrialização no Brasil (1930-1966): Notas para uma futura comparação com o caso argentino. In $36^{\circ}$ Encontro Anual da Anpocs. Águas de Lindoia.

Potash, R.A. 1984. Perón y el G.O.U. Los documentos de una logia secreta. Buenos Aires: Editorial Sudamericana.

Prestes, A.L. 1999. Tenentismo pós-30. Continuidade ou ruptura? Rio de Janeiro: Paz e Terra.

Romero, J.L. 2005. Las ideas políticas en Argentina. Buenos Aires: Fondo de Cultura Económica. 2006. História contemporânea da Argentina. Rio de Janeiro: Zahar Editor.

Rouquié, A. 1975. Radicales y desarrollistas. Buenos Aires: Schapire Editor.

Sábato, J.F. La clase dominante en la Argentina Moderna. Formación y características. Buenos Aires, CISEA, Grupo Editor Latinoamericano, 1988.

Saes, D.A.M. 1991. Classes médias e política no Brasil (1930-1964). In B. Fausto, ed. História Geral da Civilização Brasileira. O Brasil Republicano (Sociedade e Política, 1930-1964). Rio de Janeiro: Difel.

Schneider, B.R. Politics within the State. Elite Bureaucrats and Industrial Policy in Authoritarian Brazil. Pittsburgh: University of Pittsburgh Press.

1999. The Desarrollista State in Brazil and Mexico. In M. Woo-Cumings, ed. The Developmental State. Ithaca/London: Cornell University Press.

Sheahan, J. 1982. Early industrialism and violent reaction: Argentina and Brazil. Discussion Paper of the Institute of Development Studies at the University of Sussex. Brighton.

Sidicaro, R. 2002. Los tres peronismos. Estado y poder económico (1946-55/1973-76/1989-99). Buenos Aires: Siglo Veintiuno Editores Argentinos.

Sikkink, K. 1991. Ideas and Institutions. Developmentalism in Brazil and Argentina. Ithaca/London: Cornell University Press.

Stone, L. 1972. Prosopography. In F. Gilbert; S.R. Graubard, eds. Historical Studies. New York/London: W.W. Norton \& Company.

Thorp, R. 1998. The Latin American Economies, 1939-1950. In L. Bethel, ed. Latin America: Economy and Society since 1930. Cambridge, UK: Cambridge University Press.

Triberger, E.K. 1978. Revolution from Above. Military bureaucrats and development in Japan, Turkey, Egypt, and Peru. New Jersey: Transaction Books.

Vartianen, J. 1999. The Economics of Successful State Intervention in Industrial Transformation. In M. Woo-Cumings, ed. The Developmental State. Ithaca/London: Cornell University Press.

Waisman, C.H. 1987. Reversal of Development in Argentina. Postwar counterrevolutionary policies and their structural consequences. Princeton: Princeton University Press.

Weber, M. 1981. The Social Psychology of the World Religions. In H.H. Gerth; C. Wright Mills, eds. Essays in Sociology. Oxford: Oxford University Press.

Wirth, J.D. 1970. The Politics of Brazilian Development (1930-1945). Stanford: Stanford University Press.

Woo-Cumings, M. 1999. Introduction: Chalmers Johnson and the Politics of nationalism and Development. In , ed. The Developmental State. Ithaca/London: Cornell University Press.

Wynia, G.W. 1978. Argentina in the Postwar Era. Politics and economic policy making in a divided society. Albuquerque: University of New Mexico Press.

\section{Outras Fontes}

Alemann, R. 1973. Entrevista ao Proyecto de Historia Oral del Instituto Torcuato Di Tella. Buenos Aires. Jauretche, A. 1971. Entrevista ao Proyecto de Historia Oral del Instituto Torcuato Di Tella, Buenos Aires. Morales, A.G. 1972. Entrevista ao Proyecto de Historia Oral del Instituto Torcuato Di Tella, Buenos Aires. Pinedo, F. 1973. Entrevista ao Proyecto de Historia Oral del Instituto Torcuato Di Tella. Buenos Aires. Ribeiro, C.A. 1981. Casimiro Ribeiro I (depoimento, 1975/1979). Rio de Janeiro: CPDOC.

Dicionário Histórico-Biográfico do Brasil. CPDOC, versão online. 


\section{ABSTRACT}

The article analysis the concept of Developmental State and its usefulness to comparatively think the cases of Brazil and Argentina. The research design is comparative and the empirical evidences are gathered from the extensive literature on the subject and interviews with policy-makers from both countries. The research revealed that political and state elites are very important for explaining the differences in the industrialization performance of Brazil and Argentina. The comparative research, based on a concept itself devised through comparative research, has contributed to a better delimitation of the non-economic causes of the development of both countries.

Keywords: Developmental State; Brazil; Argentina; industrialization; 1930-1966. 